\title{
Operant GSR conditioning of high and low autonomic perceivers'
}

\author{
WILLIAM A. GREENE AND THOMAS C. NIELSEN 2 \\ EASTERN WASHINGTON STATE COLLEGE
}

The effect of contingent and noncontingent reinforcement on unelicited GSRs was assessed for High and Low Autonomic Perceivers. From a group of $160 \mathrm{Ss}$, the $20 \mathrm{Ss}$ who scored highest and the 20 Ss who scored lowest on Mandler's Autonomic Perceptibility Questionnaire were given $10 \mathrm{~min}$. of rest, $16 \mathrm{~min}$. of reinforcement, and $10 \mathrm{~min}$. of extinction. The effect of the reinforcer was limited to the Low Autonomic Perceivers.

Recently results have been reported to support the contention that the frequency of unelicited GSRs can be modified by different reinforcement contingencies (Crider, Shapiro, \& Tursky, 1966; Fowler \& Kimmel, 1962; Greene, 1966; Kimmel \& Hill, 1960; Kimmel \& Kimmel, 1963; Rice, 1966; Senter \& Hummel, 1965; Van Twyver \& Kimmel, in press).

The present study was designed to determine whether these frequency changes could be related to Autonomic Perceptibility. Mandler (1958) developed a paper-pencil test whose scores correlate with autonomic activity. For our initial investigation we have assumed that Mandler's Autonomic Perceptibility Questionnaire (APQ) is indicative of autonomic feedback and that this feedback can be related to conditioning. We hypothesized that Ss who are more aware of their autonomic activity, i.e., score highly on Mandler's test, and are reinforced whenever they emit a GSR, would condition better than Ss who have little autonomic awareness, i.e., score low. Furthermore, if high autonomic perceivers are reinforced whenever they are.not emitting a GSR they should emit fewer GSRs than low perceivers reinforced in the same manner. These hypotheses follow, since high perceivers would "know" the state of their autonomic activity when they were reinforced, while the low perceivers would be unable to differentiate the "feeling" of responding from not responding.

Method

Subjects. Introductory Psychology enrollees $(\mathrm{N}=160)$ at Eastern Washington State College were given the $\mathrm{APQ}$. Forty Ss (28 women and $12 \mathrm{men}$ ) of the original number were assigned to a High (H) or a Low (L) APQ group; the Ss so assigned were from the high and low ends of the distribution. These two groups were divided further (using randomized blocks) into two paired subgroups, one of which received contingent reinforcement (C) while the other received noncontingent reinforcement (NC).

Apparatus. The GSR was amplified and recorded by a Fels-Dermohmmeter and Esterline-Angus recorder from chrome finger electrodes attached to the first and third fingers of $S$ 's right hand. Each $S$ was run in a dimly-lighted quiet room, and wore sound attenuating earphones. The advance of a digital counter in front of $S$ was the reinforcing stimulus.

Procedure. The Ss were instructed to relax. A 10 min. habituation period was followed by $16 \mathrm{~min}$. of reinforcement during which, for the Contingent Ss, all responses $\geq 1 \%$ of the basal resistance "caused" $\mathrm{E}$ to advance the counter. Noncontingent $S s$ received points spaced over $1 \mathrm{~min}$. periods only when no GSRs were occurring. The number and time of delivery of noncontingent points was determined by the particular contingent $S$ to which a Noncontingent $S$ was paired (Fowler \& Kimmel, 1962). In both Contingent and Noncontingent groups all responses beginning 1 to 5 sec. after reinforcement delivery were defined as elicited GSRs and were neither counted nor reinforced. The reinforcement period was followed by $10 \mathrm{~min}$. of extinction.

Results

A response was defined as any unelicited GSR $\geq 1 \%$ of the S's base resistance. These responses were counted in 2-min. blocks and subjected to a square root transformation.

Habituation. The transformed response frequencies during the last $4 \mathrm{~min}$. of habituation were examined for each of the four groups. Analysis of variance showed no significant differences among the groups $(F<1)$ indicating that the groups wer $\in$ not different before introduction of the reinforcer.

Acquisition. To compare the effect of the reinforcer on the different groups during acquisition and extinction, the square root transform of each 2-min. block was expressed as a percentage of the number of responses during the last $4 \mathrm{~min}$. of habituation for each $\mathrm{S}$.

The means of each separate group were: $\mathrm{HC}=101.78 \%$, $\mathrm{HNC}=95.35 \%, L C=115.80 \%$, and $\mathrm{LNC}=91.11 \%$. Thus, the major source of variation was between the Contingent and Noncontingent Low Perceivers.

Figure 1 presents the transformed response frequencies during the $16 \mathrm{~min}$. of reinforcement and the $10 \mathrm{~min}$. of extinction for the $\mathrm{L}$ groups. Figure 1 indicates that the LC group responded more than the LNC group during the entire $16 \mathrm{~min}$. of reinforcement, and, in addition, the LC group responded above the $100 \%$ base throughout reinforcement. Although conventional analysis of variance failed to support the apparent differences, the size and direction of the differences were of considerable interest so Duncan's Multiple Range Test (1955) was used (Edwards, 1960, p. 136). Duncan's test supported the apparent overall difference between the LC and the LNC groups during acquisition, $p<.01$. 


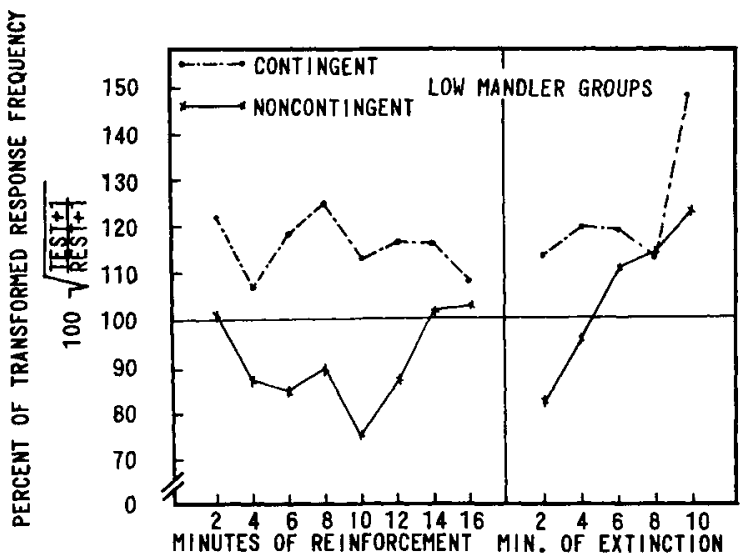

Fig. 1. Transformed response frequencies during the $16 \mathrm{~min}$. of reinforcement and the $10 \mathrm{~min}$. of extinction for the Low Mandler groups.

The Duncan test yielded additional statistically significant differences between the overall performance levels during acquisition: $\mathrm{HC}=101.78 \%$ vs. $\mathrm{LNC}=91.11 \%, \mathrm{p}$ $<.05$; the mean of the LC group at $115.80 \%$ was different from each of the following-HNC $=95.35 \%$, $\mathrm{p}<.01$; and $\mathrm{HC}=101.78 \%, \mathrm{p}<.01$. The difference between HC and HNC was not statistically supported.

Extinction. There was virtually no difference between the High $A P Q$ groups during extinction. The right-hand part of Fig. 1 shows the extinction curves for the Low APQ groups. The large difference apparent during the initial minute diminished over time. Statistical analysis indicated that only the first 2-min. block approached significance $(t=2.13, d f=1 / 18, p<.10)$. Discussion

The original prediction-that $\mathrm{HAPQ}$ Ss would be more sensitive to the reinforcement contingencies than L APQ Ss-was not confirmed. In fact, the data indicated that the opposite occurred. Briefly, the following three explanations are advanced to account for these results:

1. The point is not a sufficient reinforcer as defined by Holland \& Skinner (1961) for the H APQ Ss. Why this should be the case is not readily apparent.

2. Being "aware" of one's autonomic activity may hinder any attempt to modify this activity-at least under the conditions of this experiment. The tenability of this hypothesis must be investigated further.

3. The $H$ APQ Ss may have found the instructions difficult to follow, as they would "know" when they were or were not relaxing. This difficulty may have led to an over-emphasis upon "trying" to relax which interfered with the conditioning process. Further research with "instructions" as the independent variable is indicated.

\section{References}

Crider, A., Shapiro, D., \& Tursky, B. Reinforcement of spontaneous electrodermal activity. J. comp. physiol. Psych., 1966, 61, 20-27.

Duncan, $_{3}$ D. B. Multiple range and multiple $F$ tests. Biometrics, $1955,11,1-42$.

Edwards, A. L. Experimental design in psychological research. (Rev. ed.) New York: Rinehart, 1960.

Fowler, R. L., \& Kimmel, H. D. Operant conditioning of the GSR. J. exp. Psychol., 1962, 63, 563-567.

Greene, W. A. Operant Conditioning of the GSR using partial reinforcement. Psychol. Rep., 1966, 19, 571-578.

Kimmel, H. D., \& Hill, Frances A. Operant conditioning of the GSR. Psychol. Rep., 1960, 7, 555-562.

Kimmel, Ellen, \& Kimmel, H. D. A replication of operant conditioning of the GSR. J. exp. Psychol., 1963, 65, 212-213.

Mandler, G., Mandler, Jean, \& Uviller, Ellen. Autonomic feedback: The perception of autonomic activity. J. abnorm. soc. Psychol., $1958,56,376-383$.

Rice, D. G. Operant conditioning and associated electromyogram responses. J. exp. Psychol., 1966, 71, 908-912.

Senter, R. J., \& Hummel, W. F. Suppression of an autonomic response through operant conditioning. Psychol. Rec., 1965, 15, 1-5.

Van Twyver, H. B., \& Kimmel, H. D. Operant conditioning of the GSR with concomitant measurement of two somatic variables. J. exp. Psychol., in press.

\section{Nores}

1. This report is based upon a paper read at the meeting of the Washington State Psychological Association, Ocean Shores, Washington, May, 1966.

2. Now at Mount Hood Community College. 